\title{
La concepción de enfermedad del alma en Evagrio Póntico. Una nueva síntesis y extensión del modelo teleológico de explicación de la medicina hipocrático-galénica
}

\section{Introducción}

En los últimos años, numerosos estudios se han ocupado de señalar, de una $u$ otra manera la presencia de la medicina antigua en el pensamiento evagriano $^{2}$. Sin embargo, en esta tarea mancomunada de profundizar y di-

\footnotetext{
1 Santiago Hernán Vázquez (Mendoza - Argentina, 1984), becario Posdoctoral del CONICET (Consejo Nacional de Investigaciones Científicas y Técnicas), licenciado y profesor en Psicología y Doctor en Filosofía, profesor de Ética y Perspectivas Antropológicas de la Facultad de Ciencias de la Salud, Universidad de Mendoza, Mendoza, Argentina; e-mail: santiagohernanvazquez@gmail.com; ORCID: 0000-00022388-7172; María Teresa Gargiulo (Mendoza - Argentina, 1986), investigadora del CONICET (Consejo Nacional de Investigaciones Científicas y Técnicas) e investigador pleno del Departamento de Filosofía de la Universidad Nacional de Cuyo, Mendoza, Argentina, licenciada y Doctora en Filosofía; e-mail: gargiulomteresa@gmail.com; ORCID: 0000-0003-3580-9478.

2 Cfr. L. Dysinger, Healing Judgment: 'Medical Hermeneutics' in the Writing of Evagrius Ponticus, en: Il monachesimo tra eredità e aperture: atti del simposio 'Testi e temi nella tradizione del monachesimo cristiano', ed. M. Bielawski - D. Hombergen, Pontificio Ateneo S. Anselmo, Roma 2004, p. 75-104; Psalmody and Prayer in the Writings of Evagrius Ponticus, Oxford University Press, Oxford - New York 2005, p. 104130. Dysinger comprueba que el uso del lenguaje médico, muy común en los predecesores de Evagrio y aún en su misma atmósfera intelectual, alcanza una extensión inusitada en el monje del Ponto. Para ampliar el estudio respecto a la vinculación de Evagrio con la medicina antigua se pueden ver los estudios de Refoulé (Rêves et vie spirituelle d'après Évagre le Pontique, "Supplément de la Vie Spirituelle" 59 (1961) p. 506-511);
} 
mensionar el influjo de esta fuente en la elaboración de la concepción evagriana de enfermedad, resta aún delimitar la novedad que ella introduciría. En esta línea, esclareceremos el elemento específico de su nueva síntesis cristiana respecto de la enfermedad del alma desde la cual integraría y asumiría particulares elementos de la medicina clásica.

Cuando Evagrio se refiere a la phýsis para hablar de las enfermedades anímico-espirituales está recogiendo y haciendo aún más extensiva aquella noción tan cara a la medicina hipocrático-galenica. Al utilizar en sus escritos la expresión para phýsin para designar el estado contrario a la naturaleza, es decir, aquel por el cual el hombre se desvía de su fin natural, amplía el contenido referencial de aquel término. En un sentido literal y no meramente metafórico, hace extensiva la noción de phýsis a su explicación teleológica de las dinámicas y los movimientos del espíritu.

En el tratado Sobre la Medicina Antigua se presenta un modelo teleológico de comprensión de la phýsis. Este particular modelo de explicación teleológica significa un hito en la práctica de la medicina hipocrática continuada, más tarde, por Galeno cuyo influjo es aún más claro en Evagrio, tal como lo ha demostrado Dysinger. Aún más, la tradición hipocrática y lo que de ella gravita en la obra evagriana parece estar tamizado por la apropiación galénica.

El médico de Pérgamo asume, en efecto, aquel modelo explicativo hipocrático incluso en aquellos escritos donde desarrolla su doctrina acerca de las enfermedades del alma. Autores cristianos de los primeros siglos, particularmente Evagrio Póntico, continúan y extienden este modelo de explicación a la hora de explicitar las dinámicas psico-espirituales. Según

Guillaumont (Un philosophe au désert. Évagre le Pontique, Vrin, Paris 2009, p. 545); Messana (Notas, en: Evagrio Pontico, La preghiera, Città Nuova, Roma 1999, p. 102); Casiday (Reconstructing the theology of Evagrius Ponticus: Beyond heresy, Cambridge University Press, Cambridge 2013, p. 13); Tsakiridis (Evagrius Ponticus and Cogntive Science. A look at moral evil and the thoughts, Pickwick Publications, Eugene - Oregon 2010, p. 39); Corrigan (Thoughts that Cut; Cutting, Imprinting, and Lingering in Evagrius of Ponticus, en: Evagrius and His Legacy, ed. J. Kalvesmaki - R. D. Young, University of Notre Dame Press, South Bend 2016, p. 49-72); Peretó Rivas (El conocimiento de sí como sanación en Evagrio Póntico, en I Jornadas Internacionales de Filosofía "El cuidado de sí y el cuidado del mundo" [24, 25 y 26 de agosto de 2016], Universidad del Salvador, Buenos Aires 2016, p. 5-6, 10-13). Respecto a la presencia de las teorías médicas antiguas en la época y en la atmósfera intelectual de Evagrio puede consultarse: Alby (La medicina filosófica del Cristianismo antiguo, Universidad Católica de Santa Fe, Santa Fe 2015); Boudon-Millot \& Pouderon (Les Pères de l'Eglise face à la science médicale de leur temps, Beauchesne, Paris 2005). 
Laín Entralgo esta sería, efectivamente, la novedad que los autores cristianos introducirían en los estudios de la fisiología antigua:

La mente griega nunca llegó a vislumbrar como peculiaridad de la vida humana esa abismal región suya que después del cristianismo todos los occidentales, cristianos y no cristianos, hemos llamado y llamamos 'intimidad', cuando no nos decidimos a llamarla 'espíritu’’.

En línea con estas afirmaciones de Laín Entralgo, podríamos decir que el carácter teleológico que asume la explicación evagriana respecto al espíritu humano sería la novedad que introduciría el primer monacato cristiano en los primeros abordajes de occidente respecto a las enfermedades del alma. Esta explicación teleológica del espíritu humano formulada por Evagrio y su particular comprensión de la enfermedad ${ }^{4}$ encuentra continuidad con la medicina hipocrático-galénica. La explicación de la naturaleza física del hombre que provee la medicina clásica se revela como una base firme y coherente capaz de ser integrada y asumida en su nueva síntesis cristiana.

La citada afirmación de Lain Entralgo no quiere decir, en absoluto, que los escritos hipocráticos no hagan mención a la realidad del alma, la sensación, el movimiento y las diversas operaciones que nosotros solemos reconocer como psíquicas. En diversos tratados, tales como Sobre la enfermedad sagrada; Sobre la dieta; Dieta en las enfermedades agudas; Sobre las ventosidades; Sobre el corazón; Sobre la naturaleza de los huesos; se desarrolla, de una u otra manera, lo que puede ser reconocido como una fisiología especial de los hipocráticos en torno al alma. De acuerdo a los citados tratados, esta no es sino un principio (psyche) con una condición más sutil que la del cuerpo, "pero no 'espiritual', en el sentido que con el cristianismo llegará a tener esta palabra" - explica Lain Entralgo en su obra sobre la Medicina Hipocrática 5 .

Ciertos escritos galénicos, por su parte, también desarrollan el tratamiento para ciertas dolencias del alma ¿Cuál es entonces la aparente novedad que según el médico español introduciría el monacato cristiano?

Para responder esta pregunta y para demostrar el vínculo existente entre Evagrio Póntico y la noción teleológica de phýsis inaugurada por el

3 P. Laín Entralgo, La medicina Hipocrática, Ediciones de la Revista Occidental, Madrid 1970, p. 112.

4 Vazquez, La enfermedad del alma en el filósofo tardoantiguo Evagrio Póntico, p. $327-328$.

5 Laín Entralgo, La medicina Hipocrática, p. 180. 
Tratado sobre la Medicina Antigua y reapropiada significativamente por Galeno, presentaremos, primero, la particular comprensión teleológica de la Phýsis del mencionado tratado hipocrático. Luego, expondremos sucintamente, la asunción galénica de este particular modelo explicativo a la hora de diagnosticar y tratar ciertas dolencias el alma. Finalmente, y partiendo del ya demostrado vínculo histórico y conceptual del Póntico con las fuentes hipocráticas y galénicas, rastrearemos en la obra del monje del Ponto las expresiones katà phýsin y parà phýsin mostrando que siempre que se usan está implícita la concepción teleológica del término phýsis aunque ahora para develar los dinamismos espirituales del alma.

\section{El tratado "Sobre la Medicina Antigua". Un nuevo objeto para la práctica de la medicina}

El tratado Sobre la medicina Antigua compone - junto con El pronóstico, Sobre la medicina antigua, Sobre la dieta en las enfermedades agudas, y Aforismos - el conjunto de escritos medulares del extenso Corpus Hippocraticum. Su fecha de composición puede situarse entre los años 440 y 400 a. C., probablemente es posterior a Pronóstico, Sobre la enfermedad sagrada y Sobre la dieta en las enfermedades agudas ${ }^{6}$. Se inscribe en línea con un largo esfuerzo de la tradición hipocrática por delimitar la tarea médica de aquella medicina popular que recurría a prácticas mágicas, hechicerías y remedios supersticiosos. Pertenece, por tanto, a un momento culmen de la cultura griega caracterizado por su confianza en la razón humana en tanto ella es capaz de entender y dar cuenta del orden de la phýsis.

En primer lugar, cabe aclarar que el tratado no es un escrito en contra de la medicina antigua - como podría pensarse. Todo lo contrario, el autor demuestra que la medicina antigua se presenta en sus inicios como una práctica científica en la medida que busca una explicación causal y racional acerca del orden y la proporción de los elementos del cuerpo a través de la alimentación. Ciertamente el autor señala algunos errores y delimita

6 La opinión hoy más generalizad considera a este tratado como un típico escrito de Cos. Nadie duda, en todo caso, de que se trata de uno de los grandes escritos de la colección hipocrática; y, en general, se admite que, si no es obra de Hipócrates, sí se admite unánimemente que está próxima a sus enseñanzas o a su influjo. Cf. M.D. Lara Nava, Sobre la Medicina Antigua, Introducción, en: Tratados Hipocráticos, vol. 1, Gredos, Madrid 1983, p. 127. 
aún más las preguntas que le competen a la medicina. Pero ello no implica que desconozca que fueron sus antecesores los que instauraron este arte en virtud de un objeto.

El propósito del autor Sobre la medicina antigua es dar cuenta de carácter científico de la práctica médica. La defiende frente a detractores que llegan incluso a negar su existencia. Los autores hipocráticos estaban preocupados por establecer la medicina como un arte o techne contra aquellos que sostenían que la medicina era solo una cuestión de tuche ${ }^{7}$. Para probar el estatuto científico era necesario entonces mostrar no sólo el éxito de sus resultados terapéuticos, sino también demostrar que los resultados se debían al conocimiento causal que se poseía respecto al tratamiento médico. De aquí que el autor no se limite a justificar la medicina en función de las prácticas de sus antepasados, sino que procura delimitar dichas prácticas - tal como apunta Laín Entralgo ${ }^{8}$ - en virtud del conocimiento causal de un objeto.

En la primera parte del escrito el autor describe el objeto de la medicina antigua cómo el metron, la medida, el número, y proporción entre elementos. La buena krasía. "En la alimentación - escribe el autor - hay que apuntar a una cierta medida" ". El médico debe descubrir la medida de los alimentos según como sea cada tipo de constitución.

Al definir dicho objeto la medicina antigua manifiesta su asunción de la doctrina filosófica de los elementos que predominaba en los filósofos jonios. El hombre es entendido como parte de un kosmos. Y, a su vez, él mismo constituye un microcosmos. Ahora bien, así como aquellos filósofos explican la aparición o la corrupción de todos los seres del cosmos mediante la asociación o disociación de estos primeros elementos, la medicina antigua define la salud o la enfermedad del hombre atendiendo justamente al equilibrio dinámico entre los elementos que componen su cuerpo. La salud no es sino una isomoira, es decir, una proporcionalidad entre los elementos que componen el organismo. En cambio, el desorden, apokrisis (disgregación) o la dyskrasía (mala mezcla), la ausencia o la monarquia

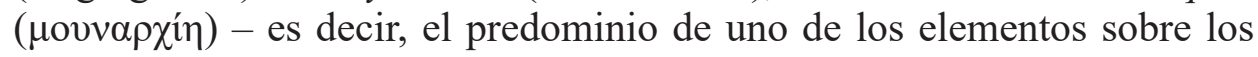
demás - se comportan como causa de la enfermedad ${ }^{10}$.

7 Recordemos que la cuestión acerca dela tuche era un tema característico del pensamiento griego en la segunda mitad del siglo V a.C.

8 Laín Entralgo, La medicina Hipocrática, p. 140.

9 Hippocrates, De Prisca medicina IX, trad. introducción y notas M.D. Lara Nava, en: Tratados Hipocráticos, vol. 1, ed. C. García Gual, Gredos, Madrid 1983, p. 146.

10 Hippocrates, De Prisca medicina XIV, p. 153. 
Pero en el capítulo 13 el autor abre ya su crítica a esta medicina antigua. Y, a través ella, comienza a mostrar la necesidad de reformular o de delimitar aún más el objeto de la práctica medicina.

Asume la doctrina del desequilibrio como causa de la enfermedad, pero rechaza como una simplificación excesiva la reducción de tratamiento médico a la búsqueda de los contrarios. La medicina antigua en orden a conseguir el equilibrio entre los elementos que componen el cuerpo del paciente recurre el método de alopatía o tratamientos por los contrarios. Este tipo de terapia dicta que los contrarios son curados por los contrarios: "contraria contrariïs curantur". A través del justo medio entre los contrarios el médico restablece el equilibrio propio de la physis.

El autor de nuestro opúsculo comparte con sus predecesores la doctrina de que la medicina debe buscar la buena mezcla o equilibrio. No obstante, señala su limitación en la medida que dicha doctrina no atiende a los principios activos o la dynamis especifica de los elementos. Su argumento es que no se puede determinar la proporción u orden de los alimentos si se desconocen sus principios activos. Esta situación la describe no sin una cierta ironía:

¿Qué decir? ¿Era que su mal lo causaba lo frio y se curó al administrarle las cosas calientes, o afirmaremos lo contrario? Creo yo que el que así fuera interrogado se vería en un gran aprieto, porque quien hizo el pan ¿qué fue lo que quito al trigo: lo caliente, lo frio, lo seco o lo húmedo?; y porque lo que se ha entregado al fuego y al agua, y además en su elaboración han intervenido otras muchas cosas que tienen su virtualidad y naturaleza propias, ha perdido algunos de sus componentes, pero se ha combinado y mezclado con otros ${ }^{11}$.

Para que la medicina pueda determinar propiamente la buena proporción o mezcla de los alimentos debe conocer los principios activos de cada uno de ellos. Pues para descubrir si hay desequilibrio entre los humores del organismo, cómo y dónde se ha originado la enfermedad y, consiguientemente, cuál debe ser también el remedio, es necesario conocer - con la mayor exactitud posible - los principios activos de los humores y la respectiva respuesta que éstos producen en el organismo. El médico no cura simplemente administrando el elemento contrario a lo que aparentemente produjo el malestar. Para curar, y para hacerlo racionalmente, debe conocer la dynamis propia de cada elemento o de la com-

11 Hippocrates, De Prisca medicina XIII, p. 151. 
binación o mezcla de cada uno de los componentes que administra al organismo humano:

Lo que no entiendo es de qué manera, con sus supuestos, curan a los hombres los que mantienen aquella teoría, desviando el arte de este método hacia el de los postulados. Porque no creo que ellos hayan descubierto algo que por sí mismo sea "lo caliente", "lo frio", "lo seco" o "lo húmedo", sin que sea coparticipe con algún otro tipo de principio. Pienso, por el contrario, que emplean los mismos alimentos y bebidas que utilizamos todos y que a lo uno le atribuyen el ser caliente, a lo otro frio, y a lo de más allá seco o húmedo. Porque recomendar a un enfermo que tome algo caliente sin más no conduciría a nada, ya que inmediatamente le preguntara que cosa, con lo que se verá obligado a divagar o tendrá que recurrir a alguna de las que son corrientes ${ }^{12}$.

Lo que daña al hombre no es lo seco, lo húmedo, lo caliente o lo frío. Lo que perjudica es "la fuerza de cada cosa y lo que puede haber en ella de excesivo"13. Luego, el remedio que se necesita para una enfermedad no es simplemente contrarrestar un síntoma con su elemento contrario. "Los hombres no tienen fiebre simplemente por culpa de lo caliente"14. El autor argumenta que lo caliente podría curar o enfermar según sean los principios activos de la sustancia caliente. En sí mismas las sustancias calientes pueden tener "principios activos opuestos entre sí" 15 . Puede ocurrir que existan males ocurridos que se deban al frio o al calor sin que estos estén combinados por ninguna otra cualidad. En este caso podrían curarse por el elemento contrario. Pero en el resto de los casos el médico debe buscar la causa de la enfermedad en los principios activos y en la mutua combinación de los mismos ${ }^{16}$. Aún más agrega que "de todos los principios activos que hay en el organismo, el frio y el calor son lo que menos influencia tienen". Pues "el calor se equilibra con el frio y el frio con el calor"17. El autor pasa a considerar al calor y al frio como principios activos secundarios, mientras que lo acido, lo salado, lo dulce y otros humores, no definidos en número, serán contemplados como principios básicos.

\footnotetext{
2 Hippocrates, De Prisca medicina XV, p. 154.

3 Hippocrates, De Prisca medicina XIV, p. 152.

14 Hippocrates, De Prisca medicina XVII, p. 157.

15 Hippocrates, De Prisca medicina XV, p. 155.

16 Hippocrates, De Prisca medicina XIX, p. 158-159.

17 Hippocrates, De Prisca medicina XVI, p. 155.
} 
Mediante diversas pruebas, testimonios y comparaciones el autor sostiene que la medicina antigua es incapaz de curar o de dar una explicación científica o causal de la enfermedad. En su lugar propone repensar el objeto del arte médico presentando la dynamis como la verdadera explicación causal de la enfermedad y la salud.

Hay en cada cosa grandes principios activos muy distintos entre sí. El que no se da cuenta de esto o no lo hace objeto de conocimiento al observarlo ¿cómo podrá siquiera conocer algo de los padecimientos en el hombre? Pues este se resiente y sufre alteraciones, en un sentido u otro, por la influencia de cada uno de esos principios, y de ellos depende la vida del hombre sano, la del que se recupera de una enfermedad y la del enfermo. De ahí que conocer estas cosas, y no otras, sea sin duda lo más imprescindible y útil ${ }^{18}$.

He aquí el nuevo objeto de la medicina: la dynamis que posee cada cosa y que forma parte del hombre en virtud de su misma dieta.

El término dynamis deriva del verbo dunamai que significa afectar. De aquí que al ser sustantivado se lo traduzca generalmente como cualidad, propiedad, poder, principio activo. Nos referiremos a él en esta última acepción en cuanto que corresponde mejor a la idea de una entidad simple y real, caracterizada por una actividad que provoca en el organismo efectos específicos observables. El autor reconoce las cualidades, tales como el calor o el frio, como fuerzas o capacidades específicas que afectan al cuerpo. Entiende la dynamis como el movimiento característico de las sustancias. O de modo inverso, la manifestación operativa de estas sustancias es reconocida como su dynamis.

En el capítulo 22 escribe: "Por principio activo entiendo el grado máximo en intensidad y fuerza de cada uno de los humores". Cada cosa posee una operación, un comportamiento especifico que se explica en virtud de sus cualidades y de sus propiedades morfológicas. Evidentemente que a mayor cantidad de humores, mayor será la intensidad con la que operen sus principios activos. Pero la forma específica del comportamiento o del efecto de un humor está determinada por sus cualidades y no sólo por su cantidad. El autor hipocrático no establece una confrontación o dialéctica entre lo cuantitativo o lo cualitativo. Por el contrario, establece entre estos accidentes propios una verdadera complementariedad explicativa.

18 Hippocrates, De Prisca medicina XIV, p. 152. 
El médico debe estudiar la dinámica o la virtud propia de los humores o de la enfermedad pues solo así podrá descubrir la estructura natural de la physis del cuerpo la cual se erige en el principio normativo de su techné iatriké. Sus tratamientos terapéuticos consisten en intervenir respetando el orden de la naturaleza. Debe averiguar dónde puede intervenir para ayudar el proceso natural, encaminándolo hacia su curación. De aquí que el autor de nuestro escrito insista en presentar a la dynamis como el verdadero objeto de la medicina. La tarea del médico no es entender la naturaleza humana desde su origen material sino inferir la finalidad de su desarrollo, es decir, estudiar el desarrollo dinámico del paciente en vista a alcanzar una naturaleza sana.

Ahora bien, esta transición de la práctica médica hacia un nuevo objeto parece incorporar un nuevo modelo causal de explicación científica. A saber, un modelo que exige dar cuenta no solo de los constituyentes materiales del objeto sino de su naturaleza y comportamiento propio.

Al sustituir el objeto de la medicina, el autor está presentando - aunque quizás de un modo tácito o implícito - una nueva concepción acerca de lo que debe ser la explicación científica. No está simplemente remplazando la doctrina de los elementos por la de los humores. Lo que cambia fundamentalmente es la pregunta causal desde la cual se analiza el objeto de la medicina. Una enfermedad, malestar o dolencia debe ser explicado - según él no tanto por referencia a las causas materiales (como puede ser la presencia de elementos puros en la dieta y por la consecuente administración de su contrario) sino por referencia a los fines propios que determinan el curso y los efectos que éstos tienen sobre el organismo según su cualidad y cantidad. El nuevo modelo de explicación médica debe sustituir la pregunta jónica acerca de los arjé (la cuestión acerca de lo elementos constitutivos primordiales del universo) por la de los principios activos o dynamis de los humores. Pues lo importante para poder curar no es resolver la cuestión de “¿cómo se ha formado (el hombre) y de qué está compuesto?” - tal como se dice en el capítulo 20 - sino ¿cómo se comportan recíprocamente los alimentos, los humores del organismo, y los órganos internos en relación a la salud?

Si se nos permite pasar de una instancia descriptica a un nivel hermenéutico podemos decir que el concepto de dynamis admite la presencia de fines reales en la physis. Pues si la dynamis es la fuerza de cada alimento, humor u órgano para poder hacer algo, ese algo sólo puede ser definido en vistas a un fin. Cada humor, cada órgano se mueve hacia un fin interno al desarrollo mismo de su forma. Cada uno posee un modo de transformación 
propio en virtud de su forma. El fin de toda dynamis no es sino la actualización de una forma. Y, en este sentido, fin y forma coinciden.

De todo esto se colige que a cada elemento corresponde un lugar propio, hacia el cual se mueve naturalmente. La dynamis propia del fuego es calentar, y la del agua, hidratar. El fin de cada entidad es su propia forma. El movimiento de las sustancias hacia un fin procede del desarrollo mismo de sus naturalezas. De este modo, la naturaleza opera como el principio interno del desarrollo y al mismo tiempo como el resultado o fin de dicho movimiento. La physis posee un telos que determina el camino que debe seguir todo proceso natural del organismo. Esta teleología es una propiedad intrínseca a la estructura de los órganos internos y a los humores del cuerpo y los alimentos.

Ciertamente en numerosas pasajes de los tratados hipocráticos la physis es entendida como el principio genético de todas las cosas naturales. La palabra physis tiene su raíz en el verbo phyein que significa nacer, brotar o crecer. En este sentido se la comprende en su condición de arkhe o de causa eficiente y material de cada una de las cosas. No obstante, desde la primera mitad del siglo $\mathrm{V}$ - tiempo donde es contextualizado históricamente nuestro escrito - la palabra physis adquiere también otro sentido que es complementario con éste. La phýsis es entendida también como el ordenamiento dinámico a un fin.

Las explicaciones teleológicas son, en último término, explicaciones acerca de la existencia de ciertas entidades en virtud de aquello que hacen, es decir, en términos de una finalidad inherente a sus procesos y estructuras. En este sentido creemos que el Tratado Sobre la medicina antigua cumple con la estructura básica de una explicación teleológica.

\section{La incorporación galénica del modelo teleológico en su doctrina respecto a las enfermedades del alma}

Galeno es el heredero de este particular modelo teleológico inaugurado por el opúsculo hipocrático Sobre la enfermedad sagrada. A continuación expondremos sucintamente cómo el médico de Pérgamo - en su Diagnóstico y tratamiento de las pasiones del alma de cada uno y en Diagnóstico y tratamiento de los errores del alma de cada uno, da cuenta de ciertas dolencias del alma desde este particular modelo explicativo.

Nuestro médico-filósofo reconoce como enfermedades del alma a desequilibrios que no son primariamente y en cuanto tales humorales, 
sino que tienen una sintomatología orgánica. En este sentido, predica la noción de pathos a diversos agentes de carácter psíquico, cognitivo y moral que pueden significar una disfunción en el organismo humano. En un lenguaje aristotélico podríamos decir que a pesar del carácter a-somático, intencional o anímico de estos agentes los reconoce como sujetos pasibles del enfermar en cuanto que se constituyen como la causa propia de una concomitante disfunción humoral. Se trata de movimientos anímicos que están siempre acompañados, como de su principio material, por una transmutación orgánica que puede provocar una disfunción humoral.

En el siguiente texto Galeno parece delimitar taxativamente el objeto epistémico que le compete tanto al filósofo como al médico. Mientras el primero debe ocuparse de modelar las costumbres del alma, el médico debe atender al cuerpo:

Según el filósofo sólo hay que modelar las costumbres del alma, pero el médico debe atender el cuerpo [...]. La ira, el llanto, la cólera, el dolor, una preocupación innecesaria o el insomnio desarrollan en los cuerpos la fiebre y originan grandes enfermedades. De este modo, se producen pereza del pensamiento y necedad ${ }^{19}$.

Sin embargo, en unas líneas más adelante, explica que las mismas pasiones o disposiciones psíquicas pueden provocar grandes enfermedades. Esta disquisición es la que nos permite inferir el aspecto formal desde el cual sería legítimo, según él, que el médico también investigue lo que en principio es objeto del filósofo o moralista. Las disposiciones psíquicas o costumbres del alma sea la cólera o la ira también son objeto de su incumbencia en tanto y en cuanto ellas pueden ser causa de una disfunción humoral que afecta a la salud del cuerpo. En Galeno se aprecia el descubrimiento intra-cientifico que la enfermedad humana no puede ser explicada exclusivamente desde la realidad corporal. Sin perder de vista el objeto delimitado de su práctica médica entrevé los dinamismos cognitivos que inciden en la physis humana.

En Symp. Diff. Galeno distingue la enfermedad de sus síntomas ${ }^{20}$. Define la enfermedad como la causa que primariamente impide realizar

19 Galenus, De Sanitate Tuenda VI 40, 8-17. Notas, índices y trad. de Inmaculada Rodríguez Moreno, Sobre la conservación de la salud, Ediciones Clásicas, Madrid 2016.

20 Galenus, De symptomatum differentiis 50-51K, trad. I. Johnston, On the Differences in Symptoms, en Galen on Diseases and Symptoms, Cambridge University Press, Cambridge - New York 2006. 
una función. El síntoma, en cambio, es el mismo daño o alteración de la función. También en Ars. Med. 307-310 asegura que el médico debe conocer no solo la composición humoral de las partes del cuerpo son también las causas de sus disfunciones ${ }^{21}$. Luego, al médico en cuanto médico le compete estudiar las afecciones del alma en la medida que ellas pueden ser causa primaria de una ruptura de la armonía de los componentes humorales del cuerpo humano. En este sentido, las pasiones y los errores cognitivos son concebidas por él, no como sujetos per accidens sino como sujetos propios del enfermar humano.

Las causas procatárticas o agentes morbosos que dañan una determinada función pueden ser - al entender de Galeno - de carácter físico o psíquico:

Vamos a estudiar en este tratado las causas de los síntomas siguiendo un orden extraído de las diferencias que hay entre ellas. Hay únicamente tres géneros de síntomas y el primer razonamiento está basado en el primero de estos géneros, que decimos ser el daño de la función. Pero las funciones son dos según el tipo de su sustancia: físicas y psíquicas ${ }^{22}$.

En línea con estos dos textos citados podríamos decir que en la medida que las pasiones se comportan como causas primarias del enfermar se les puede predicar con propiedad el concepto de enfermedad. Luego al médico en tanto médico le compete estudiar ciertas afecciones del alma en la medida que ellas pueden ser causa de una ruptura de la armonía de los componentes humorales del cuerpo humano.

En Diagnóstico y tratamiento de las pasiones del alma de cada uno y Diagnóstico y tratamiento de los errores del alma de cada uno, Galeno señala los conflictos pulsionales y cognitivos que desencadenan propiamente las afecciones anímicas. En este sentido, la tesis que expone en Las facultades del alma siguen los temperamentos del cuerpo (Quod animi mores corporis temperamenta sequntur) según la cual las disfunciones humorales son causa per accidens de las afecciones anímicas, se ve complementada por la tesis propuesta en estos dos últimos tratados: a saber, que los movimientos de las facultades del alma - sean esta de naturaleza pasional o cognitiva - se erigen como la causa propia del enfermar anímico.

Galeno sitúa la cuestión acerca de la salud del alma en las coordenadas de un modelo explicativo teleológico. Destaca la necesidad de llevar a cabo

21 Galenus, Ars. Medica 307-310, trad. P.N. Singer, Art of Medicine, en Galen: Selected Works, Oxford University Press, Oxford - New York 1997.

22 Galenus, De Sanitate Tuenda VII 85. 
una investigación anatomo-fisiológica de la estructura del alma, argumentando que solo conociendo la dynamis o principios intrínsecos de cada una de sus partes (o facultades) será posible identificar la función lesionada y discriminar la mejor forma de curarla. Atendiendo a la naturaleza de cada parte se puede distinguir la virtud y el tratamiento que le corresponde a cada una:

Es útil para los médicos conocer el lugar [del alma hegemónica] para aplicar los remedios cuando la facultad lógica está dañada; pero los filósofos no utilizan este conocimiento ni para descubrir la diferencia entre las virtudes ni para el entrenamiento mismo. Porque si la parte hegemónica del alma está en la cabeza permitirá que podamos adquirir prudencia y templanza y justicia y virilidad (andreían) con una enseñanza y entrenamiento distintos que si está localizada en el corazón ${ }^{23}$.

El médico debe conocer y diferenciar anatómica y fisiológicamente las partes del alma para poder diagnosticar y determinar las causas, el pronóstico y el tratamiento para las particulares dolencias del alma. La distinción entre las distintas facultades del alma con sus respectivas sedes orgánicas así como la cuestión acerca de la virtud propia de cada facultad, le permitirá por ejemplo identificar cómo las pasiones ejercen una alteración negativa y perjudicial en las cualidades sensibles de los órganos ${ }^{24}$.

El exceso de las pasiones afecta al alma porque significa fisiológica, anatómica o funcionalmente una desproporción entre las facultades del alma. La ira y el miedo - explica Galeno - producen una alteración en la acción natural del corazón ${ }^{25}$. Fisiológicamente la primera puede ser descripta como una exacerbada ebullición de calor del corazón mientras el miedo se manifiesta como un enfriamiento corporal. De este modo el desorden de las pasiones afectan a la salud corporal en tanto alteran de alguna manera la dynamis propia de los órganos corporales.

Las pasiones son reconocidas como patológicas en la medida que suponen una alteración, remoción o pérdida de un orden o proporción. Las emociones son el movimiento natural, la energeia propia, del apetito irascible y del concupiscible. Pero en la medida que éstas son excesivas o inmoderadas constituyen una verdadera afección (pathos) de estas facultades

23 Galenus, De Placitis Hippocratis et Platones 779, 8-16, trad. Phillip de Lacy, On the doctrines of Hippocrates and Plato, 3 vol., Akademie-Verlag, Berlín 2015.

24 Galenus, De Placitis Hippocratis et Platones 5, 270, 9-16.

25 Galenus, De Placitis Hippocratis et Platones 6, 3, 2-6. 
del alma y de todo el cuerpo. Pues debido a su falta de mesura se tornan movimientos contrarios a la naturaleza de esa parte del alma ${ }^{26}$. Galeno escribe que descubrir cuál es la causa de las afecciones del alma "nos ayuda a comprender qué significa vivir de acuerdo a la naturaleza" 27 .

Pero no solo las pasiones del apetito sino también los juicios o creencias del alma son pasibles de enfermar. En PHP 4.2.25-26 Galeno admite dos tipos diferentes de afecciones del alma: los juicios errados y las pasiones. Logos y pathos son causas diferenciables de la enfermedad del alma ${ }^{28}$.

En Pecc. Dig. Galeno explica que él denomina error en sentido estricto a aquellos juicios sobre bienes y males que se deben no a un desorden de las pasiones sino a una falla en el razonamiento del $\operatorname{logos}^{29}$. Estos juicios erróneos manifiestan una falta de entrenamiento del entendimiento para distinguir entre argumentos verdaderos, falsos y probables $^{30}$.

Los errores consisten en un mal razonamiento o juicio de valor sobre el bien o el mal de un objeto, persona o circunstancia, pero particularmente se refiere a un juicio errado respecto al fin de la vida. "El origen de muchos errores es una suposición falsa sobre el fin de la vida. En ella se originan los errores individuales como de una raíz"31. La materia fundante de todos los tipos de errores que pueden convivir en un alma enferma es aquel error cognitivo que se pronuncia respecto a los "mayores bienes" de la vida. En este sentido, Galeno juzga como indispensable para poder elegir una forma de vida conforme a nuestra naturaleza racional, instruirse en el método lógico o demostrativo ${ }^{32}$.

Cuando el médico filósofo quiere referirse a "un juicio errado sobre la finalidad de la vida" - es decir, a lo que él entiende por error en un sentido

26 Galenus, De Placitis Hippocratis et Platones 6, 1, 6-7; 6, 1, 14-16.

27 Galenus, De Placitis Hippocratis et Platones 5, 470, 6-12.

28 Galenus, De Animi Cuiuslibet Peccatorum Dignotione et Curatione 5, 77, ed., trad., introducción y notas de P.N. Singer, Galen: Selected Works, Oxford University Press, Oxford - New York 1997: “Ahora es posible comprender claramente en qué se diferencia la pasión del error. Imaginemos que un hombre haya elegido como doctrina hacer el bien a los hombres, sobre la base de que ese era su verdadero fin. Pero por causa del sueño, la pereza, la búsqueda del placer o algún motivo semejante, renuncia a ayudar: en este caso es engañado por una pasión. Por otro lado, si uno ha juzgado bueno procurarse solamente placer o serenidad y por esa razón se abstiene de ayudar a sus conciudadanos o a miembros de la familia cuando son víctimas de una injusticia, esa falla se debe a una opinión desafortunada, no a una pasión".

29 Galenus, De Animi Cuiuslibet Peccatorum Dignotione et Curatione 5, 64, 3.

30 Galenus, De Animi Cuiuslibet Peccatorum Dignotione et Curatione 5, 72.

31 Galenus, De Animi Cuiuslibet Peccatorum Dignotione et Curatione 5, 77.

32 Cf. Galenus, De Animi Cuiuslibet Peccatorum Dignotione et Curatione 5, 66, 91. 
estricto - usa propiamente el término de hamartemata ${ }^{33}$. Así se refiere a las afecciones que padece el logistikon, es decir, errores de tipo intelectual acerca de la finalidad de la vida que traen como consecuencia un desorden moral en el sujeto que los padece ${ }^{34}$. Por ejemplo, la opinión de que el dinero es un bien no es un hamartemata, sino la opinión según la cual "el dinero es el mayor bien" o "no vale la pena vivir sin dinero"35. En este sentido la avaricia se presenta no solo como un movimiento de la pasión sino fundamentalmente como un juicio errado: como la falsa suposición de que el dinero es el mayor bien.

\section{El modelo médico teleológico en Evagrio Póntico. La significatividad del uso de las expresiones katà phýsin/parà phýsin}

El modelo de explicación teleológica de la phýsis significa un hito en la práctica de la medicina hipocrática. Este modelo explicativo prosperó en los desarrollos galénicos; particularmente - tal como acabamos de mostrar - cuando éste último da cuenta de ciertas dolencias del alma.

Ahora bien, la presencia de este modelo hipocrático-galénico en la obra de Evagrio Póntico podría ser demostrada de diversos modos. Un camino posible para dilucidar esta apropiación evagriana, consiste en identificar y analizar las expresiones kata phýsin y para phýsin a lo largo de todos sus escritos. Dichas expresiones, con claras resonancias griegas y de frecuente y significativa aparición en el corpus evagriano, podrían revelar la continuidad del modelo médico clásico en la obra evagriana, particularmente la concepción teleológica de dicho modelo.

El contexto temático natural del uso de estas expresiones es aquel que tiene que ver con la enfermedad y/o las dolencias del alma. Es importante indicar, por lo tanto, que Evagrio nunca se ocupa de definir el término enfermedad (vóøoৎ) sino que supone una definición en la que claramente se pueden adivinar fuentes filosóficas y médicas clásicas. El horizonte cristiano desde el cual Evagrio piensa y reflexiona acerca del enfermar del alma supone no

33 Cf. Galenus, De Animi Cuiuslibet Peccatorum Dignotione et Curatione 5, 85, 5; $5,59,5 ; 5,59,11 ; 60,5 ; 60,10 ; 61,5 ; 63,9 ; 63,15 ; 64,3 ; 76,12 ; 77,2 ; 77,5 ; 77,11,12$; 77,$14 ; 78,4 ; 78,11 ; 91,7 ; 97,2 ; 103,15$.

34 También se refiere a ellos con el término $\pi \alpha \rho o ́ \rho \bar{\alpha} \mu \alpha, \alpha \tau o \varsigma$, que se puede traducir como equivocación, yerro, cosa mal vista. Esta palabra está a su vez emparentada con el verbo $\pi \alpha \rho o ́ \rho \alpha \sigma ı \varsigma, \varepsilon \omega \varsigma$ que alude a la acción de ver superficial o confusamente. П $\alpha \rho \rho \rho \alpha ́ \omega$ es mirar de reojo, con indiferencia o descuido.

35 Galenus, De Placitis Hippocratis et Platones 4, 5, 25. 
solo una continuidad sino también, en cierto modo, una traducción de la terminología y los conceptos propios de aquel modelo médico, a las realidades espirituales y a las explicaciones antropológicas y aún metafísicas.

Evagrio habla de enfermedad, de trastorno, de herida, de debilidad y lo hace al ocuparse de las realidades psíquicas y espirituales. Cuando lo hace supone una concepción de enfermedad que se aplica de modo literal, que no metafórico, a las realidades espirituales ${ }^{36}$.

A las resonancias platónicas y estoicas que encontramos tanto en la idea de que al alma pueda aplicarse, no solo de modo metafórico sino real, el término enfermedad, cuanto en la que indica que son las pasiones sus enfermedades, se suman francas evocaciones de las doctrinas médicas hipocrático-galénicas que Evagrio podría haber recibido en su formación. En efecto, a lo largo de toda su obra nos encontramos con una utilización reiterada y abundante de dos expresiones caras al corpus hipocrático y a la conceptualización ga-

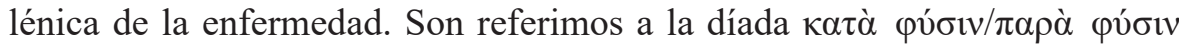
(conforme a la naturaleza/contrario a la naturaleza) ${ }^{37}$.

Evagrio sostiene que el alma está enferma porque su estado actual (postlapsario) no es acorde a su naturaleza (katà phýsin) y sus potencias tienden a moverse en un sentido contrario a la naturaleza (parà phýsin). Por ello, la apátheia es llamada por Evagrio "salud del alma” (ن̛ycíav $\psi v \chi \tilde{\eta} \varsigma)^{38}$, y las pasiones pueden ser llamadas, en sentido lato, las "enfermedades del alma", de acuerdo a la exégesis de Guillaumont ${ }^{39}$. La apátheia, en efecto,

36 Siguiendo los pasos de Platón quien de acuerdo a García Ballester y Laín Entralgo, aplica al alma las categorías médicas de modo no metafórico sino real (cfr. L. García Ballester, Alma y cuerpo, enfermedad del alma y enfermedad del cuerpo en el pensamiento médico de Galeno, "Revista de la Asociación Española de Neuropsiquiatría" 16/60 (1996) p. 724; P. Lain Entralgo, La curación por la palabra en la Antigüedad Clásica, Anthropos, Barcelona 2005, p. 128), los santos padres y Evagrio en particular, no aplican dichas categorías al alma y al espíritu solo al modo de meras imágenes analógicas sino que, como señala Larchet "[las categorías médicas] se aplican directamente a su objeto y se revelan perfectamente adecuadas a su naturaleza misma: la naturaleza humana caída está verdaderamente enferma espiritualmente, y es una verdadera curación de ésta la que se realiza" (J.-C. Larchet, Thérapeutique des maladies spirituelles, Paris 2007, p. 11).

37 Vazquez, La enfermedad del alma en el filósofo tardoantiguo Evagrio Póntico, p. 327-328.

38 Evagrius Ponticus, Traité Pratique 56, ed. A. and C. Guillaumont, SCh 171, Paris 1971, p. 631.

39 Guillaumont, Un philosophe au désert, p. 253. 
es el estado habitual katà phýsin de la parte pasional del alma en virtud del cual dicha parte contribuye a la labor contemplativa. Por el contrario las pasiones son, en tanto enfermedades, movimientos parà phýsin de la parte pasional, lo cual significa contrarios a aquellos fines que Dios ha dado a las potencias pasionales (ser auxiliares de la contemplación). Ahora bien, estos posibles movimientos parà phýsin encuentran su raíz última en el estado contranatura por antonomasia, en el cual el nous caído se introduce cuando se desprende de la unidad ${ }^{40}$ : la ignorancia, estado parà phýsin del nous, causante de todos los desórdenes. Esta es la enfermedad originaria e inherente al hombre, aquella que afecta el centro de su persona y que desorganiza todo su psiquismo.

Pero veamos cómo van apareciendo las expresiones katà phýsin y parà phýsin en el pensamiento del Póntico. Un lugar importante de su obra en el que el tópico aparece significativamente cinco veces es el tratado Sobre

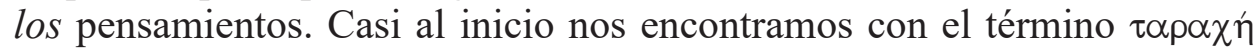
(trastorno, desorden, perturbación) designando el movimiento parà phýsin de la parte pasional del alma. Unas páginas más adelante, en el quinto capítulo, aquel término griego reaparece, verbalizado esta vez ( $\tau \alpha \rho \alpha ́ \sigma \sigma \omega)$, para hablar de los demonios y su acción cuando la potencia irascible de la parte pasional se actualiza en un sentido contrario a su naturaleza ( $\pi \alpha \rho \dot{\alpha} \phi v \sigma \iota v$

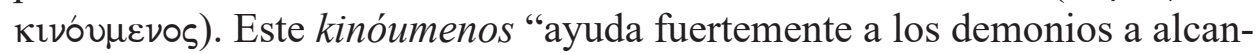
zar su fin", es decir, a impedirnos conocer ${ }^{41}$.

La causa final de la acción de los demonios sobre las naturalezas racionales es alejarlas del fin propio que el Creador ha puesto en ellas. Por su parte, el sector pasional del alma puede o no ordenarse a ese fin propio.

El hombre se hace semejante al animal (' $\alpha \lambda \hat{\gamma} \gamma \omega \nu \zeta \omega v)$ cuando la actividad pasional no está guida por el intelecto y se mueve en contra de la naturaleza (parà phýsin), insistirá nuestro autor en el capítulo 18 del mismo tratado. Los demonios perturban, desordenan, trastornan ( $\tau \alpha \rho \dot{\alpha} \sigma \sigma \omega)$ la parte pasional del alma, dirá Evagrio nuevamente, cuando la ponen en movimiento en contra de su naturaleza. Es importante entender aquí que en la cosmología evagriana los demonios son también naturalezas racionales (caídas más profundamente), con el poder para introducir palabras

40 Cfr. S. Vazquez, Algunas precisiones sobre el concepto de "monás" en Evagrio Póntico y su importancia en la comprensión de la enfermedad del alma, "Estudios Filosóficos" 68/198 (2019) p. 343-361.

41 Evagrius Ponticus, Kephalaia gnostica III 41: “Acerca de la contemplación de los seres y de la ciencia de la Trinidad, los demonios y nosotros sostenemos un gran combate; ellos queriendo impedirnos conocer y nosotros buscando aprender". 
y representaciones de cosas y personas en la imaginación de los hombres (de quienes han aprendido su lenguaje después de estudiar) ${ }^{42}$, y con la posibilidad adicional de tocar sus cuerpos y engendrar trastornos de diversa índole. En todos los casos estos espíritus malignos persiguen el objetivo de agudizar la enfermedad propia del hombre generando estados y movimientos parà phýsin que lo alejen crecientemente del conocimiento, de la ciencia espiritual. Es decir que, además de introducir palabras e imágenes con una valencia afectiva determinada, una conmoción pasional parà phýsin, los demonios pueden también tocar el cuerpo de distintas maneras. Resulta de interés detenerse por un momento en lo señalado al respecto por nuestro autor, pues aquí puede verse cómo su concepción espiritual se integra naturalmente en su obra con una concepción procedente claramente de la medicina.

En efecto, mediante esta acción física, los demonios generan movimientos parà phýsin. El capítulo 23 del citado tratado "Sobre los pensamientos", se refiere a esto. Los demonios tocan los párpados y enfrían la cabeza provocando así un estado de somnolencia parà phýsin, señala en dicho capítulo ${ }^{43}$. Este influjo demoníaco de tipo físico también se ejerce significativamente sobre los humores del cuerpo. Esta es una idea que Evagrio indica especialmente en su tratado Sobre la oración ${ }^{44}$. Los de-

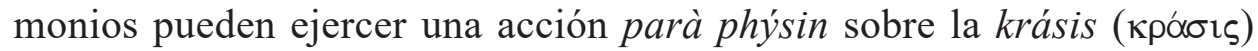
del cuerpo produciendo efectos negativos que puedan alejar al hombre del conocimiento. Parece estar operando aquí la concepción hipocrático-galénica de la krásis como la composición y el equilibrio de los cuatro humores fundamentales en que consistiría la salud, y la condición parà phýsin de su desequilibrio ${ }^{45}$. Como en Galeno, esta krásis del cuerpo tiene para Evagrio una conexión con la vida psíquica y moral del hombre. Más aun, a semejanza de la idea que Galeno desarrolla, por ejemplo, en Quod Animi Mores Corporis temperamenta Sequntur (Las facultades del alma

42 Evagrius Ponticus, Kephalaia gnostica IV 35, p. 151.

43 No es este el único lugar donde Evagrio se refiere al tocamiento físico que pueden ejercer los demonios. Además de los que referiremos, pertenecientes al tratado Sobre la Oración, encontramos los siguientes: Kephalaia gnostica I 68, p. 49; VI 25, p. 227; Contro i pensieri malvagi. Antirrhetikos II 45; IV 22; IV 36, ed. de Valerio Lazzeri, Qiqajon, Magnano 2005, p. 76, 101, 104.

44 Evagrio Póntico, Sobre la Oración 63 y 68, en: Evagrio Póntico, Obras Espirituales, ed. González Villanueva y Juan Pablo Rubio Sadia, Ciudad Nueva, Madrid 1995, p. 249, 251.

45 Lain Entralgo, La Medicina Hipocrática, p. 185-194. 
siguen los temperamentos del cuerpo $)^{46}$, para Evagrio muchas acciones o movimientos del alma derivan de la krásis del cuerpo. Por ello la acción del demonio se orienta muchas veces, como venimos diciendo, a desequilibrar dicha krásis, a producir una akrasía que es el término que utiliza Evagrio en los capítulos 63 y 83 del tratado Sobre la Oración ${ }^{47}$, a fin de provocar en el alma fantasías, pensamientos o reflexiones que la alejen de su fin último que es el conocimiento. Por lo demás, y en virtud de ese circuito de causalidad recíproca que se establece entre la krásis del cuerpo y los movimientos del alma, Evagrio también reconduce al hervor de una pasión el desencadenamiento de una akrasía ${ }^{48}$. De este modo lograr que las pasiones se orienten de modo katà phýsin es también, para Evagrio, equilibrar armónicamente esa krásis.

Pero volvamos a nuestro rastreo de aquella díada de que hace uso Evagrio para hablar del funcionamiento normal o anormal del alma. Habíamos dicho que en el tratado Sobre los Pensamientos la expresión $\pi \alpha \rho \grave{\alpha} \phi v ́ \sigma u$ aparece cinco veces. La última de estas apariciones se halla en el capítulo 36 y hace referencia al objetivo de los llamados logismoi. Estos pensamientos malvados que son los logismoi, nacidos de las pasiones enfermas, buscan, a su vez, profundizar el movimiento contranatura de la parte pasional del alma. De allí que en Evagrio la palabra logismoi tenga, por lo general, un sentido peyorativo pues se trata de la actividad cognitiva propia del alma enferma ${ }^{49}$. No obstante, Evagrio distingue a veces los $l o-$ gismoi en este sentido de los pensamientos comunes y corrientes. Y lo hace precisamente usando las dos expresiones que estamos rastreando aquí. En

46 Galenus, Quod Animi Mores Corporis temperamenta Sequntur 3, 779: "El temperamento del cuerpo transforma las funciones del alma" dice Galeno en una fórmula que sintetiza la idea que transmite esta obra, cuyo título ya resulta sugerente. Trad. Juana Zaragoza Gras, Las facultades del alma siguen los temperamentos del cuerpo, Gredos, Madrid 2003.

47 Evagrio parece estar usando aquí el término akrasía no en el sentido de ausencia de mezcla como haría suponer la alfa privativa, sino como "mala mezcla". Quizá el término griego preciso sería el de duskrasia. Éste, al igual que en la obra evagriana, tampoco es usado, nos anoticia Laín Entralgo, en el Corpus Hipocrático, "pero sí, y con todo rigor, la idea por él expresada", dirá el español (Lain Entralgo, La Medicina Hipocrática, p. 193). En los puntos 18 y 19 del tratado hipocrático Sobre la Medicina Antigua, por ejemplo, vemos desplegada esta idea de la akrasía como mala mezcla de los humores

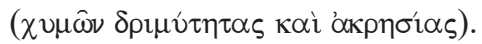

48 Cfr. Evagrio Póntico, Sobre la Oración 83, p. 255.

49 Cfr. Santiago Vazquez, La noción de logismoí en Evagrio Póntico: el correlato cognitivo de las pasiones enfermas, "Endoxa: Series Filosóficas” 43 (2019) p. 67-90. 
su opúsculo Skemmata, en efecto, indica en dos ocasiones, que hay pensamientos katà phýsin y parà phýsin. Los primeros son los que tienen por objeto, verbigracia, la madre, el padre, la esposa o los hijos. Los segundos son los que derivan de las pasiones, de los demonios y de una elección libre

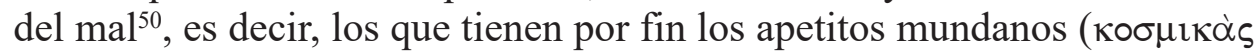

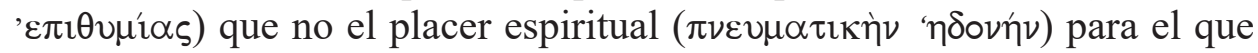
el ser racional está hecho, es decir, el conocimiento ${ }^{51}$. En este sentido, los logismoi - sobre los que Evagrio insiste a lo largo de toda su obra - son, a la manera de Galeno, errores cognitivos respecto a personas, circunstancias, objetos y, en definitiva, respecto del fin de la vida. En efecto, los logismoi pueden hundir al hombre en la ignorancia respecto de su propio fin profundizando así su enfermedad ${ }^{52}$, poniendo en la propia satisfacción a que impulsa filautía (de la que nacen, a su vez, todos los logismoi $i^{53}$ ), el fin de toda la vida. Precisamente porque son razonamientos falsos la labor terapéutica que, de acuerdo a Evagrio, puede ejercer el llamado gnóstico está destinada a desarticular sofismas, o, como señala Forthomme, porque tienen un elemento lógico los logismoi "son susceptibles de ser reencontrados por el impacto de una palabra" 54 .

El ejemplo acerca de la avaricia que hemos traído a colación al referirnos a los errores cognitivos en Galeno, también puede hallarse en términos confluyentes en Evagrio para quien la avaricia es uno de los ocho logismoi fundamentales que se instala en forma de engaño respecto al lugar que ha de ocupar el dinero en la vida. En el horizonte cristiano y monástico de la renuncia a los bienes de este mundo, los razonamientos falsos acerca del lugar del dinero en la vida del monje siguen teniendo vigencia y así este monje puede pensar, de acuerdo a la minuciosa identificación de los razonamientos falsos que hace Evagrio en su Antirrhético ${ }^{55}$, que es un gran

50 Evagrius Ponticus, Skemmata 45 y 56, en: W. Harmless - R.R. Fitzgerald, The sapphire light of the mind: the Skemmata of Evagrius Ponticus, ed. William Harmless y And Raymond R. Fitzgerald, "Theological Studies” 62 (2001) p. 528.

51 Evagrius Ponticus, Traité Pratique 24, p. 556; Kephálaia Gnostica III 64, po. 123.

52 Cfr. Vazquez, La noción de logismoi en Evagrio Póntico, p. 84.

53 "El primero de todos los pensamientos es el de la filautía; después de éste, vienen

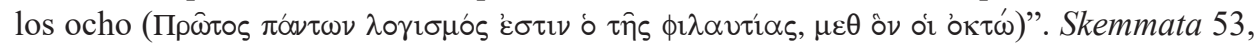
p. 528.

54 B. Forthomme, L'expérience de la guérison, Les Empêcheurs de penser en rond, Paris 2002, p. 73.

55 En esta minuciosidad y perspicacia del Póntico para identificar con precisión las muchas sugestiones cognitivas que proceden de los ocho logismoi (lo cual es realizado principalmente en la obra Antirrhético, pero no solo en ella), no podemos sino evocar 
mal digno de angustia haber dejado la herencia de los padres ${ }^{56}$, o que la necesidad de dinero es apremiante y contra ella no vale la confianza en la Providencia ${ }^{57}$, o busca pretextos como el de hospitalidad ${ }^{58}$ o el del bien de los hermanos (o incluso el de comprar las Sagradas Escrituras) ${ }^{59}$, para conseguir más dinero o bienes; o, en fin, cree que en la adquisición de riquezas visibles está la dicha ${ }^{60}$.

Pero volvamos a nuestro recorrido que nos puede permitir dimensionar mejor el influjo de aquella medicina clásica en Evagrio. También en el Tratado Práctico encontramos la expresión parà phýsin. En el capítulo 93, dicha locución es usada junto a su contraria, katà phýsin, para designar, respectivamente, el uso enfermo y el sano de la potencia irascible. En el primer caso, se desvirtúan las facultades de nuestra alma, en el segundo

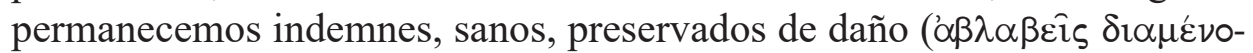
$\mu \varepsilon v)$. También aquí no podemos sino evocar lo que señalara Galeno respecto al movimiento natural del apetito irascible y al inmoderado o excesivo que provoca una desproporción en las facultades del alma.

En el capítulo 86 del mismo tratado, el Póntico ya ha precisado cuándo el alma racional se halla en un estado katà phýsin, a saber, cuando cada una de sus partes tiende al fin que el Creador ha inscripto en ellas. Antes, en el capítulo 24 de esta obra, ya nos había anticipado esta idea indicándonos que orientar la parte irascible al combate con los hombres era orientarla contra su naturaleza ( $\pi \alpha \rho \dot{\alpha} \phi v \delta \iota v)$, pero orientarla al combate con los demonios y a la lucha por el placer espiritual era lo natural y propio de ella. Si se direcciona en sentido contrario a este último, el intelecto se oscurece y cae de la ciencia, lo cual es decir que profundiza su enfermedad propia que es la ignorancia.

A propósito, un texto de Képhalaia Gnostica resulta iluminador pues nos sugiere en qué sentido un movimiento parà phýsin de la parte pasional del alma puede obstaculizar la contemplación: "Lo mismo que aquellos cuya vista está enferma y miran al sol son molestados por sus lágrimas y ven fantasmas en el aire, así también el nous puro, cuando ha sido trastor-

aquel entrenamiento del entendimiento para distinguir entre argumentos verdaderos, falsos y probables, que reclamaba Galeno en su obra Diagnóstico y tratamiento de los errores del alma de cada uno, según vimos más arriba.

56 Evagrius Ponticus, Antirrheticus III 16, p. 86.

57 Evagrius Ponticus, Antirrheticus III 23, p. 88.

58 Evagrius Ponticus, Antirrheticus III 25, p. 88.

59 Evagrius Ponticus, Antirrheticus III 35, p. 90.

60 Evagrius Ponticus, Antirrheticus III 46, p. 92. 
nado por la cólera, no puede recibir la contemplación espiritual; sino que ve como una niebla que reposa sobre los objetos"61.

El movimiento contranatura de la parte pasional impide al intelecto acceder a la realidad profunda de las cosas. Dicho movimiento crea una realidad ficticia que se interpone entre la inteligencia y la realidad, crea fantasmas.

La idea que está operando de fondo es que orientar parà phýsin una potencia es, últimamente, desviarse de la ciencia. En efecto, aquellos fines katà phýsin de las dos potencias pasionales son katà phýsin en la medida en que se orientan al fin último que es la obtención de la ciencia.

En Ocho Espíritus de la Maldad aparece la expresión katà phýsin con

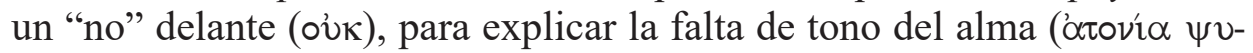
$\chi \bar{\eta} \varsigma$ ) que padece acedia: "La acedia es una falta de tono del alma, pero una falta de tono que no es según la naturaleza"62.

Lo que la caracteriza a la acedia, el último de los ocho logismoi, es, según este texto, una falta de tensión. Se trata de una carencia de energía para perseverar en la vida que busca la ciencia. Por la acedia, el alma, como indica Peretó Rivas, "deja de estar tensionada hacia su fin, siguiendo de ese modo aquel deseo insaciable que le era connatural, para relajarse en la consecución de deseos contrarios a su naturaleza [...] El alma decae, flácida y débil, perdiendo su orientación tensionante hacia Dios o la Unidad, a la que está llamada a regresar" ${ }^{63}$. La atonía que define a la acedia es así un estado de carencia parà phýsin, en la medida en que implica un cese abrupto de la tensión hacia el fin que es la ciencia. Por ello el acedioso es llamado en este mismo capítulo $\alpha \sigma \theta \varepsilon v \omega \hat{\omega} \nu$ (enfermo) ${ }^{64}$.

61 Evagrio Póntico, Kephálaia Gnostica VI 63, p. 243.

62 Evagrio Póntico, Gli otto spiriti della malvagità 13, ed. F. Moscatelli, San Paolo, Milano 1996, p. 54.

63 R. Peretó Rivas, El Carro Alado platónico y la eutonía en la dinámica psicológica de Evagrio Póntico, en: Studia Patristica Vol. LXXVI: El platonismo en los Padres de la Iglesia, ed. M. Vinzent, Peeters, Leuven 2017, p. 62, 65. Este asunto también es profundizado por Cataldo en su libro Vita come tensione nell'antropologia di Evagrio Pontico, Ecumenica Editrice, Bari 2007, p. 101-108.

64 Evagrio Póntico, Gli otto spiriti della malvagità 13, p. 56. Evagrio utiliza dos términos al hablar de enfermedad, sea ésta del cuerpo o del alma como en este caso de la acedia. Los términos son vó $\sigma \circ \varsigma$ y $\alpha \sigma \theta \dot{\varepsilon} v \varepsilon ı \alpha$. En la utilizacion del termino $\alpha \sigma \theta \dot{\varepsilon} v \varepsilon ı$ en este sentido, nuestro autor parece estar articulando una tradición antropológica cristiana que se enraíza en la Sagrada Escritura, y más precisamente en la versión griega de los LXX del libro sagrado. Juan Carlos Alby se ha ocupado detenidamente del análisis y el rastreo de este término en la Sagrada Escritura y en la antropología cristiana primitiva. 
También en Képhalaia Gnostica nuestro autor ha usado en tres ocasiones estas dos significativas expresiones que estamos rastreando. Debemos recordar que el texto griego original completo de esta obra no se conserva y que, en su lugar, tenemos dos versiones en siríaco, una en armenio, una retroversión al griego hecha por Frankenberg y algunos fragmentos griegos originales desperdigados en tres compilaciones distintas. En este caso tenemos la fortuna de que dos de las menciones de aquellas expresiones se conservan en el original griego. La primera conservada en el original pertenece a la oración inicial del kephálaion 64 de la primera centuria: "La vida

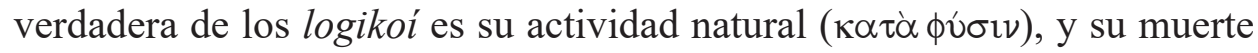
su actividad contranatura ( $\pi \alpha \rho \dot{\alpha} \phi v ́ \sigma \iota v)^{"}{ }^{65}$.

Como bien indica Ramelli, este texto es paralelo a los de los kephálaia 40 y 41 de la misma centuria ${ }^{66}$, donde Evagrio habla de la prioridad ontológica de la vida sobre la muerte y de la salud sobre la enfermedad. El peca-

Aunque este autor no se ocupe de Evagrio Póntico claramente la conclusión a la que arriba se aplica también a nuestro filósofo del desierto. En efecto, Alby indica que "El significado primario de asthéneia tanto en el Antiguo como en el Nuevo Testamento es el de enfermedad corporal. No obstante, en la medida en que la antropología cristiana avanzó hacia formulaciones más elaboradas, la concepción de hombre sostenida por los primeros cristianos como un ser en relación con lo divino a través de su dimensión espiritual y con el cosmos creado por Dios, produjo una expansión de su campo semántico generándose otros indicadores de la debilidad connotada por el término, tales como la flaqueza en la fe o la que deviene de las injurias y persecuciones. El horizonte de la enfermedad se amplió más allá de la esfera corporal hacia aspectos propios de la experiencia religiosa". J.C., La asthéneia en la antropología cristiana primitiva, "Scripta Mediaevalia" 4/1 (2011) p. 24-25. Evagrio resulta un ejemplo eminente de lo que refiere Alby. En su obra puede rastrearse, en efecto, esta doble significación del término $\alpha \sigma \theta \varepsilon$ $v \varepsilon i \alpha$. Como enfermedad corporal aparece, por ejemplo, en tres capítulos del Tratado Práctico: en el 40 hablando de la tentación que recae sobre alguien que está físicamente enfermó ' $\alpha \theta \varepsilon v o v \tilde{v} \tau \alpha$ 's, en el 82 refiriéndose a posibles miembros del cuerpo en estado mórbidó $\alpha \sigma \theta \varepsilon v o u ́ v \tau \omega \nu \mu \varepsilon \lambda \omega \vec{\omega}$ y en el 91 hablando de la obra del servicio de los enfermos ' $\alpha \sigma \theta \dot{\varepsilon} v o v \tilde{\sigma} i$ que los monjes podían eventualmente llevar a cabo. Designando enfermedades espirituales o del alma aparece, además de en este contexto del tratamiento de la acedia, en otros lugares que más adelante analizaremos.

${ }_{65}$ Evagrio Póntico, Kephálaia Gnostica I 64, p. 47. El texto griego corresponde, en este caso, a la compilación de Muyldermans y se halla disponible on-line en el siguiente enlace: http://www.ldysinger.com/Evagrius/02_Gno-Keph/00a_start.htm (27.05.2020): Luke Dysinger, St. Evagrius Ponticus (345-399). Gnostikos and Kephalaia Gnostika, "Monastic Spirituality Self-Study (Website)" (2020).

66 I. Ramelli, comentario a KG I, 64, en: Evagrio Póntico, Evagrius's Kephalaia Gnostica: A New Translation of the Unreformed Text from the Syriac, Writings from the Greco-Roman World, SBL Press, Atlanta 2015, p. 63. 
do, la caída, introducen la enfermedad y la muerte en las naturalezas racionales hechas para la vida divina. Aquella vida verdadera es la de la ciencia

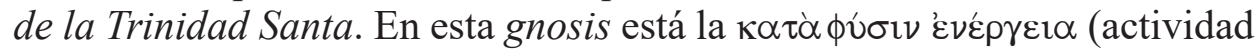
natural o acorde a la naturaleza) de que habla el Póntico en el kephálaion 64, transcripto arriba. La muerte es la caída de esa vida verdadera y, por

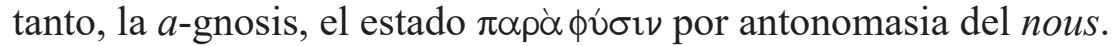

De los dos textos restantes de Kephálaia Gnostica donde nuestro filósofo hace uso de las expresiones que estamos explorando, solo uno de ellos, como dijimos, se conserva en el original griego. Se trata del kephálaion 59 de la tercera centuria. En cuanto al texto restante en el que podemos sospechar que se halla una de las expresiones griegas que estamos rastreando, solo disponemos de la retroversión griega de Frankenberg, y, desde luego, de las traducciones del texto siríaco al francés y al inglés. En este kephálaion del que no se posee el original (el 16 de la tercera centuria), Evagrio afirma que el alma perfecta es aquella cuya parte pasional o potencia pasible, actúa naturalmente o katà phýsin, como verosímilmente propone Frankenberg ${ }^{67}$. El paralelismo establecido por Ramelli de este kephálaion con el catorce de la misma centuria, resulta también esclarecedor. En efecto, son textos complementarios que comparten estructura y tema:

El alma deficiente es aquella cuya potencia pasible está inclinada hacia la vanidad $^{68}$.

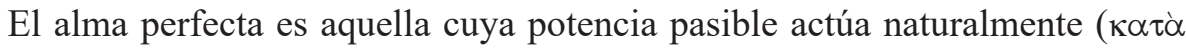
$\phi \tilde{v} \sigma(v){ }^{69}$.

En el primero, Evagrio afirma que el alma deficiente, defectuosa, da-

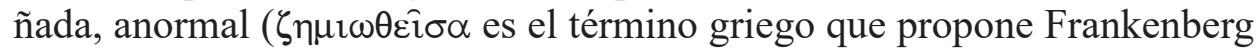
y que contempla todos esos matices que son asumidos en las traducciones al francés y al inglés) es aquella cuya parte pasional se inclina hacia la nada (traducción de Ramelli), hacia las cosas vanas (traducción de Dysinger), hacia la vanidad (traducción de Guillaumont). De este modo -y teniendo en cuenta el paralelismo que puede y debe ser establecido entre estos dos

${ }^{67}$ El texto de esta retroversión podemos hallarlo en el siguiente enlace: http://www. ldysinger.com/Evagrius/02_Gno-Keph/00a_start.htm (27.05.2020). Luke Dysinger, St. Evagrius Ponticus (345-399). Gnostikos and Kephalaia Gnostika, "Monastic Spirituality Self-Study (Website)" (2020). Ténganse en cuenta que este kephálaion es el mismo en S1 (versión retroversionada al griego) y en S2.

68 Evagrio Póntico, Kephálaia Gnostica III 14, p. 103.

69 Evagrio Póntico, Kephálaia Gnostica III 16, p. 103. 
kephálaia- Evagrio, que habla en el segundo del funcionamiento katà phýsin, nos ha especificado en el primero cuál sería la inclinación parà phýsin de la potencia pasible del alma por la cual ésta es deficiente, anormal o está dañada.

El último texto de Kephálaia Gnostica en el que encontramos la expresión es el perteneciente, como hemos adelantado, al kephálaion 59 de la tercera centuria conservado en su original griego: "Si toda la malicia es engendrada por la inteligencia, por el thymos y por la epithymia, y de estas potencias nos es posible usar bien o mal, es evidente, pues, que es por el uso contranatura de estas partes que las dolencias nos arriban"70.

Por el uso contrario a la naturaleza de las partes del alma nos arriban, nos sobrevienen ( $\varepsilon \pi \imath \sigma v \mu \beta \alpha \imath v o v \sigma \imath v)$ las $\kappa \alpha \kappa i \alpha l$. Este rico término griego evoca inmediatamente las ideas de vicio, mal, dolencia, sufrimiento.

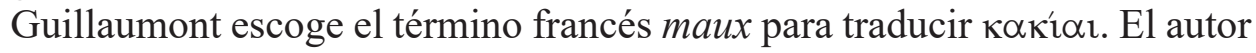
francófono opta por un término de su lengua que designa tanto los plurales dolores, dolencias, males, cuanto el de enfermedades. No nos alejamos con ello del pensamiento evagriano, pues nuestro autor utiliza muchas veces en paralelo los términos vicio y virtud, bondad y malicia, enfermedad y salud, respectivamente. Por ejemplo, en Kephálaia Gnostica I, $41^{71}$. Más aún, en el opúsculo Treinta y tres Capítulos Ordenados diferentes vicios son significativamente nombrados con denominaciones de enfermedades médicas ${ }^{72}$. Por lo demás, la apátheia, el estado de virtud, es llamada, en ocasiones, la salud del alma, como hemos visto.

En el mismo contexto temático son usadas nuestras dos expresiones en el capítulo 99 de la importante obra Capítulos de los Discípulos de Evagrio. Recordemos que esta obra reúne un conjunto de enseñanzas que, aunque no escritas directamente por Evagrio, sí rescatan lo que podría denominarse el último estado del pensamiento del monje del Ponto compilado por sus discípulos, ofreciéndonos elaboraciones novedosas acerca de tópicos típicamente evagrianos. Pues bien, además del capítulo indicado,

70 Evagrio Póntico, Kephálaia Gnostica III 59, p. 121.

71 "Si la muerte es segunda por relación a la vida, y la enfermedad segunda por relación a la salud, es evidente que la malicia también es segunda por relación a la virtud. Muerte y enfermedad del alma, en efecto, es la malicia, y la virtud es más antigua aún que el estado intermedio".

72 Evagrio Póntico, Thirty-Three Ordered Chapters 1-16, en: Evagrius of Pontus. The greek ascetic corpus, traducción y comentarios de R. Sinkewicz, Oxford University Press, Oxford 2003, p. 224-227. Respecto a este procedimiento evagriano y a su inspiración origeniana se puede ver: Dysinger, Psalmody and Prayer, p. 115-117. 
las expresiones que estamos rastreando aparecen en otros lugares más de este escrito. Sus apariciones son, desde luego, conceptualmente relevantes, pues cuando se producen lo hacen en tanto nociones fundamentales en la comprensión y cualificación del funcionamiento del alma o el mismo ser del hombre. Veamos, entonces, cómo son usadas en el mencionado capítulo, o kephálaion, 99:

La virtud consiste en hacer un uso racional y conforme a la naturaleza de las cosas indiferentes dadas por Dios, la malicia (какía) en hacer un uso contrario a la naturaleza. Aquél pues que haga un buen uso recibirá la ciencia verdadera presente en ellas, pero aquél que haga un mal uso concebirá, respecto de ellas, opiniones falsas ${ }^{73}$.

La idea de la virtud y el vicio como hábitos, respectivamente, katà phýsin y parà phýsin, se reafirma aquí, y siempre en relación con el fin propio del hombre que es la obtención de la ciencia verdadera. Llegar a la salud completa - que, como indica Evagrio en el capítulo 8 de esta misma obra y en Kephálaia Gnostica II, 15, está en esa ciencia verdadera, en la salud del estado de unidad en el que se participa del conocimiento substancial implica una disposición pasional katà phýsin que abre los ojos para ver los lógoi de las cosas. Alejarse de ella, profundizar la enfermedad, es orientar habitualmente las pasiones en un sentido contrario a la naturaleza, en una dirección diversa de la que la lleva al conocimiento, y por tanto aumentar la ignorancia respecto de las cosas que no son conocidas en su verdadera y auténtica condición.

En un sentido semejante aparece parà phýsin en el capítulo 96. Aquí el autor está interesado nuevamente en subrayar que las facultades del alma no son malas por naturaleza sino que es por su uso parà phýsin que el mal ingresa en la realidad humana. Ciertamente el mal está siendo comprendido, en línea con el capítulo noventa y nueve, como aquello que priva o aleja de la ciencia.

El capítulo 137 especifica esta afirmación general del 96 refiriéndose concretamente al movimiento de la parte irascible que el autor llama cólera. Éste posee una finalidad katà phýsin muy clara: los demonios. Es esta la serpiente que se ha de combatir con odio y expulsar y destruir con rencor. Toda cólera que tenga una finalidad distinta es parà phýsin,

73 Evagrio Póntico, Chapitres des disciples d'Évagre 99, ed. P. Géhin, SCh 514, Paris 2007. 
es decir, pasión-enfermedad en el sentido que vimos hace un momento: "No hay cólera justa, salvo aquella que es dirigida contra los demo-

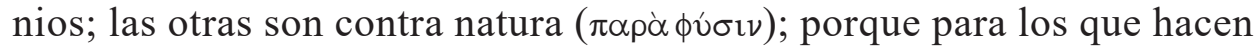
prueba de todo dulzor hacia todos los hombres encolerizarse es contra natura ( $\pi \alpha \rho \grave{\alpha} \phi v ́ \sigma \iota v) " 74$.

En suma, lo que define el funcionamiento sano o enfermo de una facultad es el hecho de que dicho funcionamiento se oriente o no al fin propio del hombre que es el conocimiento. El funcionamiento katà phýsin de las facultades del alma es el que contribuye a que el hombre supere la ignorancia. Dichas facultades han sido dadas por Dios, en efecto, como auxilios para reacceder a la ciencia de la Trinidad Santa.

Una facultad está enferma cuando su acto profundiza la ignorancia. En el caso de las "estructuras" cognitivas la coincidencia con Galeno resulta particularmente significativa. Recordemos que para el médico de Pérgamo es "una suposición falsa sobre el fin de la vida" lo que genera diversos tipos de errores cognitivos que pueden engendrar, a su vez, diversas afecciones en el alma. Los logismoi evagrianos, por su parte, consisten generalmente en razonamientos falsos que parten de supuestos erróneos prescritos por la filautía (la cual a su vez nace de una más profunda ignorancia, según hemos demostrado ${ }^{75}$ ), y en este sentido son parà phýsin.

Ahora ¿por qué las facultades se hallan inclinadas a buscar fines que no son los que el Creador ha inscripto en ellas? Porque hay una ignorancia anterior y más originaria, aquella que Evagrio pone como la consecuencia negativa inmediata de la caída ${ }^{76}$. Ella es el estado parà phýsin del $\lambda$ o$\gamma \imath \sigma \tau \iota \kappa \delta \nu^{77}$ o "parte racional" como traduce Guillaumont, y, por tanto, la enfermedad propia del alma humana en la que se enraízan el resto de los desórdenes. Esto teniendo en cuenta que esta parte racional "no es otra cosa que el intelecto, el nous, es decir, la esencia misma del ser racional, creado intelecto puro" "78, como indica Guillaumont; o, como subraya por su parte Konstantinovsky, "el verdadero yo o persona [...] el asiento de la

74 Evagrio Póntico, Chapitres des disciples d'Évagre, 137.

75 Ver nuestro artículo: La enfermedad del alma en el filósofo tardoantiguo Evagrio Póntico.

76 Evagrio Pontico, Kephálaia Gnostica I 49, p. 41.

77 Ya hemos referenciado el capítulo 86 del Tratado Práctico, donde Evagrio afirma que "El alma racional actúa según su naturaleza (katà phýsin) cuando [...] su parte racional (logistikón) percibe la contemplación de los seres".

78 A. Guillaumont, Introduction, en: Evagrio Póntico, Traité Pratique. Tome I, SCh 170, Paris 1971, p. 105. 
autodeterminación y la libertad, y, en el cristianismo, el lugar de la imagen de Dios"79. Evagrio aplica efectivamente el término ' $\alpha \sigma \theta \varepsilon v \varepsilon \varepsilon \alpha$ al intelecto caído, subrayando que esta enfermedad, este estado de debilidad, le es

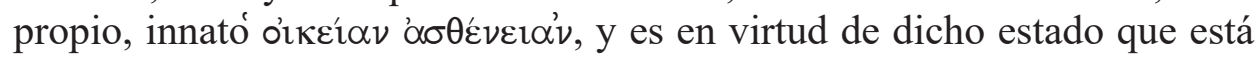
incapacitado para la contemplación ${ }^{80}$, es decir, se halla en una condición parà phýsin, teniendo en cuenta lo que afirma nuestro autor en el capítulo 86 del Tratado Práctico respecto a la contemplación como la actividad katà phýsin del logistikón.

\section{Conclusiones}

El influjo de la medicina antigua en la patrística, en general, ha sido un tópico del que se han ocupado diversos estudios. El caso de Evagrio Póntico es particularmente significativo pues el uso del lenguaje médico es abundante en su obra.

La apropiación cristiana que realiza nuestro autor de la concepción teleológica de phýsis, inaugurada por el tratado hipocrático Sobre la Medicina Antigua y continuada más tarde por Galeno, representa un caso emblemático de las primeras relaciones que se establecieron entre el primer monacato cristiano y el conocimiento secular. Evagrio encuentra en las aproximaciones profanas, particularmente en la medicina hipocrático-galénica, verdadera continuidad y sustento para su comprensión espiritual del hombre.

Ahora bien, se trata, ciertamente de una modalidad asimétrica y jerárquica donde la ciencia profana de aquel entonces es incorporada, traducida o transfigurada en una nueva síntesis cristiana. La apropiación evagriana de

79 J. Konstantinosky, Evagrius Ponticus and Maximus the Confessor The building of the Self in Praxis and Contemplation, en: Evagrius and His Legacy, ed. J. Kalvesmaki R.D. Young, University of Notre Dame Press, South Bend 2016, p. 132. En el mismo sentido, escribe Gabriel Bunge: "En las condiciones históricas y concretas que le son propias, el ser humano es una realidad compleja que se descubre como 'compuesto de un cuerpo y de un alma'. Con toda evidencia, no solo el cuerpo está constituído de varios elementos: también el alma tiene diversas 'facultades' o 'partes', según la terminología de Evagrio. Y sin embargo el hombre sabe intuitivamente que, en su ser más profundo, él es uno. Este núcleo inalienable de la persona, que Meister Eckhart llamará 'chispa del alma', Evagrio lo designa como intelecto (nous)"'. G. Bunge, Einleitung, en: Evagrios Pontikos, Praktikos oder der Mönch, Luthe-Verlag, Köln 1989, p. 26-27.

80 Evagrio Póntico, Scholies aux Proverbes, 310: "Nuestro intelecto no puede, con-

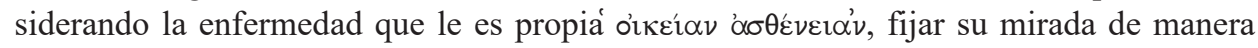
continua sobre una tan alta contemplación". 
aquella concepción teleológica de phýsis es realizada en un horizonte cristiano que asume como dato antropológico fundamental la centralidad de la dimensión espiritual en la definición del hombre. Éste es un nous caído de la unidad (monás), unido a un cuerpo y provisto de una dimensión psíquica (alma) como auxilio para retornar a la unidad. Esta particular concepción cristiana inscribe el modelo teleológico de explicación, inaugurado por la medicina, en nuevas coordenadas. Pues el fin subordinante de la phýsis estará, en el caso del hombre, trazado por la dimensión espiritual. El fin del nous (la ciencia espiritual en sentido amplio) es, en última instancia, lo que define en Evagrio la condición sana o patológica de toda la estructura anímica.

\section{The Conception of Soul Disease in Evagrius Ponticus. A New Synthesis and Extension of the Teleological Model of Explanation of Hippocratic- Galenic Medicine of Weakness of the Soul in Evagrius Ponticus}

(summary)

A long hermeneutical tradition has indicated, in one way or another, the influence of ancient medicine on the writings of Evagrius Ponticus. But the interest of our study is not only limited to exposing the sources that seem to have nourished the Evagrian understanding of the disease of the soul, but also seeks to clarify the original element from which the Monk of Pontus would incorporate the teleological model of explanation inaugurated by Hippocratic-Galenic medicine. His new Christian synthesis would inscribe in new coordinates that explanatory model of secular science. As it is stated in his writings, the subordinate end of the phýsis will be traced by the spiritual dimension.

Keywords: Evagrius Ponticus; Hippocrates; Galen; Teleological model; soul sickness; spirit

\section{La concepción de enfermedad del alma en Evagrio Póntico. Una nueva síntesis y extensión del modelo teleológico de explicación de la medicina hipocrático-galénica}

(resumen)

Una larga tradición hermenéutica ha señalado, de una u otra manera, el influjo de la medicina antigua en los escritos de Evagrio Póntico. Pero el interés de nuestro estudio no se limita únicamente a exponer las fuentes que parecen haber nutrido la comprensión evagriana de la enfermedad del alma sino que busca, además, esclarecer el elemento original desde el cual el Monje del Ponto incorporaría el modelo teleológico de explicación inaugurado por la medicina hipocrático-galénica. Su nueva síntesis cristiana inscribiría en nu- 
evas coordenadas a aquel modelo explicativo de la ciencia secular. Pues, tal como consta en sus escritos, el fin subordinante de la phýsis estará, trazado por la dimensión espiritual.

Palabras clave: Evagrio Póntico; Hipócrates; Galeno; Modelo teleológico; enfermedad de alma; espíritu

\section{Bibliografía}

\section{Fuentes}

Evagrius Ponticus, Chapitres des disciples d'Évagre, ed. P. Géhin, SCh 514, Paris 2007.

Evagrio Póntico, Contro i pensieri malvagi. Antirrhetikos, ed. de Valerio Lazzeri, Qiqajon, Magnano 2005.

Evagrio Póntico, Gli otto spiriti della malvagità, ed. F. Moscatelli, San Paolo, Milano 1996.

Evagrio Póntico, Kephalaia gnostica, ed. A. Guillaumont, PO 28, Paris 1958.

Evagrio Póntico, Scholies aux Proverbes, ed. P. Géhin, SCh 340, Paris 1987.

Evagrio Póntico, Skemmata, en: W. Harmless y A.R.R. Fitzgerald (eds.), The sapphire light of the mind: the Skemmata of Evagrius Ponticus, "Theological Studies" 62 (2001) p. 498-529.

Evagrio Póntico, Sobre la Oración, en: Evagrio Póntico, Obras Espirituales, ed. G. Villanueva y J.P. Rubio Sadia, Ciudad Nueva, Madrid 1995.

Evagrio Póntico, Thirty-Three Ordered Chapters, en: Evagrius of Pontus. The greek ascetic corpus, Traducción y comentarios de R. Sinkewicz, Oxford University Press, Oxford 2003.

Evagrio Póntico, Traité Pratique, ed. A. and C. Guillaumont, SCh 171, Paris 1971.

Galenus, De Locis Affectis, ed., trad y notas de A. Aparicio, Sobre la localización de las enfermedades, Gredos, Madrid 1997.

Galenus, Ars. Medica, ed., trad., introducción y notas de P.N. Singer, Art of Medicine, en Galen: Selected Works, Oxford University Press, Oxford - New York 1997.

Galenus, De propium Animi Cuiuslibet Affectuum Dignotione et Curatione, ed., trad., introducción y notas de P.N. Singer, Galen: Selected Works, Oxford University Press, Oxford - New York 1997.

Galenus, De Animi Cuiuslibet Peccatorum Dignotione et Curatione, ed., trad., introducción y notas de P.N. Singer, Galen: Selected Works, Oxford University Press, Oxford - New York 1997.

Galenus, Quod Animi Mores Corporis temperamenta Sequntur, ed., introd., trad. y notas de J. Zaragoza Gras, Las facultades del alma siguen los temperamentos del cuerpo, Gredos, Madrid 2003.

Galenus, De symptomatum differentiis, ed. y trad. I. Johnston, On the Differences in Symptoms. Galen on Diseases and Symptoms, Cambridge University Press, Cambridge - New York 2006. 
Galenus, De Placitis Hippocratis et Platones, ed., trad. y comentarios Ph. de Lacy, On the doctrines of Hippocrates and Plato, 3 vol., Akademie-Verlag, Berlín 2015.

Galenus, De Sanitate Tuenda (San. Tu.), ed., introd., trad., notas e índices de I. Rodríguez Moreno, Sobre la conservación de la salud, Ediciones Clásicas, Madrid 2016.

Hippocrates, De Prisca medicina, ed. García Gual, trad., introducción y notas M.D. Lara Nava, en: Tratados Hipocráticos, vol. 1, Gredos, Madrid 1983, p. 135-182.

\section{Literatura}

Alby J.C., La asthéneia en la antropología cristiana primitiva, "Scripta Mediaevalia" 4/1 (2011) p. 11-26.

Alby J.C., La medicina filosófica del Cristianismo antiguo, Universidad Católica de Santa Fe, Santa Fe 2015.

Boudon-Millot \& Pouderon, Les Pères de l'Eglise face à la science médicale de leur temps, Beauchesne, Paris 2005.

Bunge G., Einleitung, in Evagrios Pontikos, Praktikos oder der Mönch, Luthe-Verlag, Köln 1989, p. 17-43.

Casiday A., Reconstructing the theology of Evagrius Ponticus: Beyond heresy, Cambridge University Press, Cambridge 2013.

Cattaldo G., Vita come tensione nell'antropologia di Evagrio Pontico, Ecumenica Editrice, Bari 2007.

Corrigan K., Thoughts that Cut; Cutting, Imprinting, and Lingering in Evagrius of Ponticus, in: Evagrius and His Legacy, ed. J. Kalvesmaki - R.D. Young, University of Notre Dame Press, South Bend 2016, p. 49-72.

Dysinger L., Healing Judgment: 'Medical Hermeneutics' in the Writing of Evagrius Ponticus, in: Il monachesimo tra eredità e aperture: atti del simposio 'Testi e temi nella tradizione del monachesimo cristiano', ed. M. Bielawski - D. Hombergen, Pontificio Ateneo S. Anselmo, Roma 2004, p. 75-104.

Dysinger L., Psalmody and Prayer in the Writings of Evagrius Ponticus, Oxford University Press, Oxford - New York 2005.

Forthomme, B., L'expérience de la guérison, Les Empêcheurs de penser en rond, Paris 2002. García Ballester L., Alma y cuerpo, enfermedad del alma y enfermedad del cuerpo en el pensamiento médico de Galeno, "Revista de la Asociación Española de Neuropsiquiatría" 16/60 (1996) p. 705-735.

Guillaumont A., Introduction, in: Evagrio Póntico, Traité Pratique. Tome I, SCh 170, Paris 1971.

Guillaumont A., Un philosophe au désert. Évagre le Pontique, Vrin, Paris 2009.

Konstantinosky J., Evagrius Ponticus and Maximus the Confessor The building of the Self in Praxis and Contemplation, in: Evagrius and His Legacy, ed. J. KalvesmakiR.D. Young, University of Notre Dame Press, South Bend 2016, p. 128-153.

Lain Entralgo P., La curación por la palabra en la Antigüedad Clásica, Anthropos, Barcelona 2005. 
Laín Entralgo P., La medicina Hipocrática, Ediciones de la Revista Occidental, Madrid 1970. Larchet J.-C., Thérapeutique des maladies spirituelles, Paris 2007.

Messana V., Notas, en: Evagrio Pontico, La preghiera, Città Nuova, Roma 1999.

Nava Lara M.D. Sobre la Medicina Antigua, in: Tratados Hipocráticos, vol. 1, Gredos, Madrid 1983, p. 125-134.

Peretó Rivas R. El conocimiento de sí como sanación en Evagrio Póntico, in: I Jornadas Internacionales de Filosofía "El cuidado de sí y el cuidado del mundo" [24, 25 y 26 de agosto de 2016]. Buenos Aires 2016, p. 1-13.

Peretó Rivas R., La eutonía en la dinámica psicológica de Evagrio Póntico, in: Studia Patristica Vol. LXXVI: El platonismo en los Padres de la Iglesia, ed. M. Vinzent, Peeters, Leuven 2017, p. 59-66.

Ramelli I., Commentary, in: Evagrio Póntico, Evagrius's Kephalaia Gnostica: A New Translation of the Unreformed Text from the Syriac, Writings from the Greco-Roman World, SBL Press, Atlanta 2015, p. 3-374.

Refoulé F. Rêves et vie spirituelle d'après Évagre le Pontique, "Supplément de la Vie Spirituelle" 59 (1961) p. 506-511.

Tsakiridis G., Evagrius Ponticus and Cogntive Science. A look at moral evil and the thoughts, Pickwick Publications, Eugene - Oregon 2010.

Vazquez S., Algunas precisiones sobre el concepto de "monás” en Evagrio Póntico y su importancia en la comprensión de la enfermedad del alma, "Estudios Filosóficos" 68/198 (2019) p. 343-361.

Vazquez S., La enfermedad del alma en el filósofo tardoantiguo Evagrio Póntico: entre ignorancia y filautía, "Anales del Seminario de Historia de la Filosofía" 35 (2018) p. 323-343.

Vazquez S., La noción de logismoí en Evagrio Póntico: el correlato cognitivo de las pasiones enfermas, "Endoxa: Series Filosóficas” 43 (2019) p. 67-90. 